\title{
Los imaginarios urbanos: de la teoría y los aterrizajes en los estudios urbanos
}

\begin{abstract}
From a starting point of the need to return to the concept of imaginaries, this paper first reviews the various contributions to the genealogy of this concept that can be extracted from the social sciences and humanities. The paper then questions the relationship between imaginaries and space, revealing the close articulation between them from the very same conceptualization of imaginaries. Finally, the paper offers a brief review of the various studies of urban imaginaries, providing evidence of the differences between three approaches: the first dedicated to practices, the second representations and the third on the search for the articulation between practices and spatial experiences and lived spaces. Important themes that arise from these three approaches are the loss of the city, the impact of modernity on urban life, the new lifestyles linked to postmodernity and, finally, fear and the lack of security. The conclusions relate to perspectives from multiple disciplinary references, without underestimating the material dimensions of the city.
\end{abstract}

Keywords: imaginaries, city, space, representations

\section{Resumen}

Partiendo de la necesidad de un regreso sobre el concepto de imaginarios, este artículo repasa, en primer lugar, las diversas aportaciones a la genealogía del concepto que podemos extraer de las ciencias sociales y las humanidades. Enseguida nos interrogamos sobre la relación entre imaginarios y espacio, demostrando su fuerte articulación desde la misma conceptualización de los imaginarios. En la tercera parte del texto, se hace un breve repaso de los diversos estudios existentes sobre imaginarios urbanos y en particular, se diferencian tres líneas: una dedicada a las prácticas, otra centrada en las representaciones y una tercera que busca la articulación de las prácticas con la experiencia espacial y el espacio vivido. Temas relevantes que surgen de las tres líneas son la pérdida de la ciudad, el impacto de la modernidad sobre la vida urbana, los nuevos estilos de vida ligados a la posmodernidad y, finalmente, el miedo y la falta de seguridad. Se concluye sobre la necesidad de abordar los imaginarios desde perspectivas de multirreferencias disciplinarias, sin menospreciar la dimensión material de la ciudad.

Palabras claves: imaginarios, ciudad, espacio, representación 


\section{Introducción}

$\mathrm{E}$ n los últimos quince años, una parte significativa de los estudios sobre la ciudad ha tomado una orientación radicalmente distinta a la que dominaba anteriormente. Como signos anunciadores de una nueva primavera susceptible de rejuvenecer los aportes que tradicionalmente se han hecho al conocimiento de la ciudad, han florecido estudios que desde las torres de observación de las disciplinas más variadas, o en ocasiones transdisciplinarios, proponen lecturas de la ciudad diferentes a las que imperaban hasta mediados de los años setenta.

Por lo menos, es posible identificar dos orientaciones en este florecimiento: como un primer conjunto, pueden reconocerse aquellos trabajos que se interrogan sobre la esencia de la ciudad, su persistencia misma en un mundo donde la extensión inconmensurable del fenómeno que llamamos urbanización deja planear dudas sobre el carácter urbano de las morfologías materiales y los géneros de vida resultantes. Por la otra, emerge una reflexión trascendental sobre la cara oscura de la ciudad (parafraseando a Pink Floyd): la dimensión subjetiva de la producción y la apropiación de la ciudad por sus habitantes. Cara mucho tiempo disimulada por la reflexión intensa y avasalladora que las décadas anteriores se hizo sobre la materialidad de la misma, las dimensiones subjetivas se ven ahora declinadas en todas las tonalidades discursivas y disciplinarias.

Este artículo no pretende tratar ambas orientaciones, lo que sería por lo menos demasiado ambicioso en el marco de un texto de reducida extensión. Sin embargo, aun si nuestras reflexiones se dirigen a escrutinizar el tema de la subjetividad, no dejaremos totalmente de lado la primera línea de reflexiones innovadoras: en efecto, las ideas vertidas por numerosos autores sobre temas como la desaparición de la ciudad o las nuevas morfologías urbanas, no están exentas en su esencia de una fuerte subjetividad, resultado de la percepción

\footnotetext{
Investigador del Departamento de Sociología y profesor titular del programa en Geografía Humana, Universidad Autónoma Metropolitana, Campus Iztapalapa, Ciudad de México. E-mail: danielhiernaux@gmail.com.
}

particular de los fenómenos estudiados que tienen los mismos autores y de los imaginarios urbanos que atraviesan, tal flujo sanguíneo, el cuerpo de sus relatos (Hiernaux, 2006a; Levy, 2003; Soja, 2001).

Por otra parte, reduciremos nuestro análisis a la componente que se suele llamar los imaginarios urbanos, ya que el tema de la subjetividad en sí es mucho más amplio y si bien recubre plenamente el de los imaginarios, no puede ser reducido a estos. Cabe aclarar que, como se expresará posteriormente, los imaginarios atraviesan todas las esferas de la vida. En este sentido, afirmar que la subjetividad está exenta de imaginarios sería evidentemente un error conceptual. Sin embargo, no todos los estudios sobre la subjetividad hacen referencia directa a los imaginarios. Es en ese sentido, que los imaginarios en sí forman parte de la subjetividad individual y colectiva, pero también asumimos que solo reflejan una parte de la misma, y es a esa misma componente que nos referiremos en este trabajo, y no a todo el análisis de la subjetividad, lo que superaría ampliamente el ya de por sí ambicioso propósito que nos planteamos aquí.

En un primer tiempo, hemos considerado útil regresar sobre el concepto mismo de imaginario: lo anterior obedece a que la producción reciente que se reclama parte de este tema, evidencia muchas indefiniciones, asimilaciones inadecuadas y relatos fantasiosos sobre el mismo concepto. Ello es fruto de una evidente deriva, muy frecuente en temas de índole cultural y fruto de una culturalización irreflexiva presente en no pocos estudios culturales, como lo ha señalado Carlos Reynoso (2000).

Enseguida, en un segundo tiempo, explicamos la relación entre imaginario y espacio, y, particularmente, reflexionamos sobre las posibilidades de aplicación del tema al campo de los estudios urbanos. Finalmente, en un tercer momento, se hace un repaso de las tendencias de los estudios sobre imaginarios urbanos a las cuales nos orientamos, para concluir con una reflexión sobre las perspectivas de los estudios urbanos desde los imaginarios urbanos en el contexto actual, y particularmente en el caso iberoamericano. 


\section{El imaginario: genealogía y consolida- ción de un concepto}

Desde tiempos inmemoriales, la supuesta objetividad prohijada por la razón por una parte, y la subjetividad procreada por la sensibilidad por la otra, parecerían haber sido malas compañeras en el viaje intelectual de la humanidad: basta recordar, a manera de ejemplo, cómo Aristófanes se burló en su obra los Pájaros, de la pretensión de Hipodamo de Mileto, porque quería imponer la idea, descabellada para su tiempo, de que la traza de las ciudades tuviera que ser ortogonal. La filosofía occidental tradicional-que pretende ser científica y razonable- se cuidó de incorporar en sus discusiones aquella capacidad de imaginación propia de los seres humanos, que demuestra una posibilidad noética para abrirnos a otra realidad, posibilidad que la filosofía siempre ha pretendido constreñir solo a la poesía o la literatura en gene$\mathrm{ral}^{1}$, sin admitir que sea un campo fértil para sus propias reflexiones.

Por otra parte, algunos autores nos han recordado, de manera indiscutible, que la imaginación anclada en esquemas que son comunes a toda la humanidad -una cuenca semántica universal como la califica Gilbert Durand (1992)-interviene como factor actuante no solo en la construcción del pensamiento, sino también en el ámbito de la actuación individual y social de los seres humanos.

Regresando a la historia de las ideas sobre el tema, es evidente que el siglo XVIII, prohijador del gran movimiento racionalista, engendró también un rechazo y un bloqueo a las reflexiones sobre el imaginario y su relación con la vida cotidiana de los seres humanos. En ese paisaje intelectual, la imaginación fue vista más bien como una facultad negativa que implicaba, en quienes la seguían, un rechazo a seguir los caminos comunes y correctos, trazados y señalados por la aplicación de la razón en el comportamiento humano: para los pensadores de la época, la imaginación era considerada

No por azar, muchos textos utópicos, es decir en buena medida imaginarios, adoptan la forma literaria o, en nuestra época, la fílmica; siendo ciertamente esta última una gran portadora y emisora de imágenes e imaginarios, como se hace evidente en el éxito de la saga de El Señor de los Anillos, por ejemplo. como una "...potencia de embrujamiento del espíritu...” (Guenancia, 2003: p. 45). Más reservado, Descartes mismo consideró a la imaginación como una facultad del espíritu para imaginar cosas, pero sometida a la capacidad de control ejercida por la razón. Por ende, esa capacidad de imaginar se veía mutilada, es decir, incapaz de crear un mundo propio.

Las tendencias positivistas que se fueron imprimiendo de manera cada vez más decisiva en las ciencias sociales, impidieron por décadas que se pudiera desarrollar una teoría más generosa en torno al papel de la imaginación en los procesos subjetivos y vividos de la humanidad. Solo en las corrientes idealistas y subjetivistas de la filosofía (que encuentran sus bases en el pensamiento filosófico del obispo Berkeley, por ejemplo) será factible encontrar elementos que no releguen a la imaginación a la celda donde el racionalismo pretendía encerrar a las locuras humanas, sino que le asignen un papel más positivo en la vida humana.

El final del siglo XIX y los inicios del XX generaron nuevas corrientes de pensamiento, entre las cuales destaca la fenomenología, que prestaron una mayor atención y sobre todo se manejaron con cuidado y una visión menos sesgada, sobre los fenómenos ligados a la imaginación y la subjetividad. En la línea de reflexiones como las de Simmel, Husserl, Merleau-Ponty, Jung, Cassirer o Bachelard, entre otros, progresivamente se consolidará un interés creciente hacia los procesos imaginales ${ }^{2}$, que se desprenderán de la crítica racionalista, despreciativa y reduccionista que había elaborado la gran ola racionalizadora de los siglos anteriores. Así, por ejemplo, Georg Simmel recuerda que "toda relación entre los hombres hace nacer en uno, una imagen del otro" (Simmel, 1991: p. 10). A su turno los filósofos de la religión, como Mircea Eliade (1985) o Karl Kerényi (2006), aportaron elementos sumamente innovadores para explicar la formación de los mitos en las religiones tradicionales, exponiendo la presencia de lo que

La voz imaginal fue propuesta por Henri Corbin, en lugar de imaginarios, teniendo de hecho el mismo sentido, pero enfatizando su fuerza creadora (Grassi, 2005: p.16). 
Gilbert Durand llamará más tarde, los arquetipos del imaginario (Durand, 1992).

Esta confluencia de reconocimientos de todo lo relacionado con la imaginación, que en cierta forma logra constituirse en un tema relevante para las ciencias sociales al margen de la corriente positivista, se consolidará progresivamente hasta lograr una posición si no central, sí admitida y reconocida por las ciencias sociales y las humanidades. En particular, la magna obra de Gilbert Durand (1964; 1992; 1994) sobre estos temas, resulta ser un esfuerzo singular y de gran alcance, que le da consistencia al estudio de los imaginarios. Este autor desarrolla los argumentos necesarios como para que ya no sea posible negar la fuerza de los imaginarios, así como para avanzar en su reconocimiento como elemento central -aunque no único- para comprender el comportamiento humano.

Conviene entonces, aunque brevemente, introducir ahora algunas ideas en este sentido, para aclarar cómo se pueden definir términos esenciales como imaginación, imaginario, símbolo ${ }^{3}$, etc., ampliamente usados - a veces incorrectamente- por los nuevos estudiosos de los imaginarios. Como lo señala tan atinadamente Valentina Grassi, es frecuente que la expresión imaginario sea usada como una suerte de gran recipiente, que permite a todas las disciplinas asirse del mismo para cierto tipo de reflexiones (Grassi, 2005: 13).

Vale recordar que los estudios urbanos han caído en el uso indiscriminado de palabras, expresiones o pre-juicios, sobre los cuales han construido no pocas interpretaciones de las ciudades: desde la desurbanización, la dependencia, la ciudad global, la ciudad dual, pasando por la informalidad urbana, la desterritorialización hasta la ciudad fortaleza. Así, no han sido pocos los intentos por imponer voces que pretenden, cada cual en su época y en su contexto, plantearse como conceptos rectores para los estudios urbanos, casi siempre sin lograr previamente una concepción

\footnotetext{
Usaremos en este trabajo la voz símbolo en el sentido que le da Gilbert Durand, siguiendo a A. Lalande, como "...todo signo concreto evocando, por una relación natural, algo ausente o imposible de percibir” (Durand, 1964: p. 11).
}

clara y más o menos aceptada de las mismas. Conviene entonces tomarnos ese tiempo para aclarar los conceptos esenciales sobre los cuales se construyen los estudios de los imaginarios o, más bien, sobre los cuales sería deseable que se edificaran, lo que no siempre es el caso, como lo sostuvimos previamente.

Para Gilbert Durand, el imaginario se define como "...la inevitable re-presentación, la facultad de simbolización de la cual emergen continuamente todos los miedos, todas las esperanzas y sus frutos culturales desde hace aproximadamente un millón y medio de años, cuando el homo erecto se levantó sobre la tierra” (Durand, 1994: p. 77).

El imaginario funciona sobre la base de representaciones que son una forma de traducir en una imagen mental, una realidad material o bien una concepción. En otros términos, en la formación del imaginario se ubica nuestra percepción transformada en representaciones a través de la imaginación, proceso por el cual la representación sufre una transformación simbólica. El imaginario es justamente la capacidad que tenemos, de llevar esta transformación a buen término.

Otra cuestión que es importante destacar es que la representación en sí no es suficiente ni tampoco es el proceso que nos proponemos estudiar: en efecto, el imaginario aporta un complemento de sentido a las representaciones, las transforma simbólicamente para ser tanto guías de análisis como guías de acción. En otros términos, es “...una superación de la simple reproducción generada por la representación, hacia la imagen creadora" (Legros et al, 2006: p. 83). En ello yace la fuerza creativa del imaginario que rebasa la simple representación: el imaginario crea imágenes actuantes, imágenes-guías, imágenes que conducen procesos y no solo representan realidades materiales o subjetivas. En otro contexto lo confirmamos también, expresando que el imaginario es, entonces, un proceso dinámico que otorga sentido a la simple representación mental y que guía la acción (Hiernaux y Lindón, 2007).

El trabajo de Gilbert Durand introduce otras nociones que resultan útiles para esta perspectiva, como el de esquemas, arquetipos, estructuras y regímenes. Los esquemas serían una matriz fun- 
cional que articula las representaciones imaginales con los gestos reflexológicos de los individuos, estudiados por la reflexología ${ }^{4}$. Cuando dichos esquemas se enfrentan con la realidad concre$\mathrm{ta}^{5}$, se generan arquetipos que son "...instancias originarias y universales del imaginario, que se manifiestan en el nivel cultural, en los símbolos" (Grassi, 2005: p. 18) ${ }^{6}$. A su turno, en función de su reagrupamiento en torno a esquemas originales, los arquetipos pueden reunirse en estructuras y posteriormente, en un nivel mayor de generalidad, en regímenes (Grassi, 2005: p. 16) ${ }^{7}$.

\section{El espacio y el imaginario}

Gilbert Durand observa que todos aquellos autores que estudian el imaginario, han evidenciado la "insólita inmediatez de la imagen" (Durand, 1969: p. 462). La percepción transforma instantáneamente el objeto percibido en una imagen. Ello ocurre por una suerte de fulgor que trasciende toda dimensión temporal. La imaginación engendra en forma inmediata nuevas imágenes, sin más

Cabe recordar que la psicología reflexológica rusa es una perspectiva muy fisiológica, para la cual todo lo que existe es material y a esto se le denomina monismo: sólo existe una única realidad, que es la material.

Jean Chateau llama la atención sobre la articulación de los imaginarios con lo que llama consignas que son, de cierta manera, el esqueleto de nuestra imaginación. Distingue entre la consigna externa que es la imposición externa, que el individuo puede identificar como tal, y la consigna interiorizada, transformada en segunda naturaleza, que suele combinarse con la imagen percibida, dándole sentido y orientación. En otros términos, Chateau se distancia de las aproximaciones demasiado fenomenológicas, que otorgan un poder absoluto al imaginario: para él, la consigna es lo que matiza el imaginario y lo integra en esquemas socialmente construidos (Chateau, 1976: p. 223-224).

Durand señala también, que es en los arquetipos donde se logra la conjunción entre el imaginario y los procesos racionales. También nota que existe una gran estabilidad en los arquetipos, aunque "los arquetipos se ligan con imágenes muy diferenciadas según las culturas y en las cuales varios esquemas llegan a imbricarse" (Durand, 1992: p. 63).

En su obra sobre las estructuras antropológicas del imaginario (1992), Durand define dos grandes regímenes, el diurno y el nocturno, que consisten en una clasificación de las imágenes en dos grandes grupos, el primer régimen (diurno), corresponde a la dominante postural. Mientras que el régimen nocturno integra las imágenes que derivan de la dominante digestiva y copulativa, cada dominante funcionando a partir de esquemas que le son propios. preámbulos, lo que elimina toda posibilidad de duración bergsoniana en el proceso imaginario (como consecuencia de la transformación inmediata de lo percibido en imagen $)^{8}$.

Negándose, así, la afirmación de Inmanuel Kant según la cual el tiempo es la condición a priori de todos los fenómenos en general (el tiempo como intuición pura), Durand afirma entonces que "...solo queda por considerar el espacio como sensorium general de la función fantástica" (Durand, 1969: p. 472). Para el propósito de quienes estudiamos el espacio urbano y el espacio en general, esta afirmación es medular, más aun cuando el autor continúa afirmando que el "espacio, [es el] lugar de nuestra imaginación" (Durand, 1969: p. 472).

Por otra parte, Durand reconoce que las imágenes resultan marcadas por la ocularidad, la profundidad y la ubicuidad ${ }^{9}$. La primera característica -la ocularidad- responde a la primacía de la vista; la segunda -la profundidad- más que al nivel de lo geométrico, responde a cierta invitación al viaje en busca de un distanciamiento privilegiado; mientras que la ubicuidad recuerda que las imágenes no tienen patria, es decir, son universales (Durand, 1969: p. 475-477).

La espacialidad misma de las imágenes afirma, así, un lazo fundamental, quizás fundacional, entre el espacio y el imaginario, que el tiempo no puede invocar, ya que la imagen es atemporal. Esto es así, tanto porque se trata del tiempo en la memoria, como por el hecho de que traspasa las épocas históricas, como invariante cultural en su forma arquetípica. En otros términos, la preeminencia del espacio sobre el tiempo (cuyo papel es negado por Durand) en la formación de las imágenes,

\footnotetext{
Durand plantea además, que el hecho de que las imágenes se queden en la memoria, no implica que ésta sea el reflejo de una nueva modalidad de duración, sino que es una forma de volver a hacer presente instantes pasados, jugándose justamente en el transcurso temporal entre el momento en que la imagen se memorizó y el instante actual (Durand, 1969: p. 463-469).
}

9 El neologismo ocularidad propuesto por $\mathrm{Du}$ rand, se asemeja al concepto desarrollado por varios geógrafos, entre los cuales está Derek Gregory (1994), sobre la primacía de la visión en el mundo occidental moderno, como forma privilegiada de percibir la realidad. 
permite que éstas, al ser guardadas en la memoria social puedan resurgir en su forma pretérita, sin que medien procesos de transformación. La interpretación que haremos de estas imágenes pasadas no será la misma que tuvimos en otro tiempo. Así, por ejemplo cuando ciertas culturas del pasado invocaban a los seres del inframundo como referencias a imágenes de miedo, nosotros hoy en día accedemos a esas imágenes pero ya no las interpretamos de esa forma (salvo en cierto tipo de películas, por cierto) sino que le damos otra interpretación, que se deriva de nuestro Zeitgeist. Es así como el miedo actualmente lo remitimos a la imagen de otros seres (y no los del inframundo), por ejemplo narcotraficantes, sicarios y otros personajes similares. Sin embargo, nuestro actuar puede ser afectado por el sentido del miedo de la misma forma en que le ocurría con nuestros antepasados, aun si no usamos el mismo taken for granted (Berger y Luckmann, 1997), para definir las imágenes del miedo (nosotros los delincuentes, nuestros antepasados los seres del inframundo). En este sentido, y reconociendo variaciones históricas y culturales, podría ser -aunque esto merecería un análisis más profundo- que nuestro actuar presente frente al miedo sea la respuesta actual a una cuenca semántica milenaria.

El imaginario que transforma así la percepción en imagen, acordará, entonces, un interés predominante en lo que se deriva de la percepción del espacio (por la misma ocularidad) y, por ende, las imágenes espaciales conforman una parte sustancial de nuestros acervos imaginarios. Por esta razón, entre los arquetipos sustantivos que describe y analiza Durand a lo largo de su obra, emergen temas notoriamente espaciales, como la morada, el árbol, la cima, etc. De igual forma, entre los símbolos que estudia están incluidos la escalera, el campanario, la espiral, la tumba, la isla, la cueva, que derivan de esta misma presencia notoria del espacio en el análisis del autor.

El espacio urbano tiene un rol especial en la activación de nuestra capacidad de imaginación: como lo reconocía ya Simmel en su tiempo, en la ciudad el urbanita está constantemente afectado por una avalancha de estímulos visuales, que conforman una suerte de puesta bajo tensión permanente, para la percepción humana (Simmel,
1986). Así, el urbanita, mucho más estimulado visualmente que en los otros sentidos, puede tomar una actitud de repliegue que se deriva en cierta forma de hastío. No obstante, una parte sustancial de las impresiones visuales recibidas, son efectivamente transferidas instantáneamente al reservorio de imágenes que se construye progresivamente en la mente humana.

La ciudad se encuentra entonces fragmentada en nuestra mente en un sinnúmero de imágenes que no forzosamente alcanzan coherencia entre sí como significantes. Es, entonces, a partir de los esquemas previamente construidos y asimilados (que actúan como matrices de comprensión, como lo señalábamos), que podemos tejer la urdimbre imaginal que conecta entre sí las imágenes que han sido captadas a la manera de una toma fotográfica en ráfaga. Y así, es posible articularlas con los arquetipos.

En ese momento -se recordará que el proceso es atemporal, es decir no exige duración como lo señaló Durand, en opinión contraria al planteamiento de Bergson sobre la relevancia de la misma- el sujeto es capaz de pasar de la representación al acto. Para tomar un ejemplo, la oscuridad de un espacio (quizás solamente provocado por un efecto de contraste luminoso excesivo y una pérdida de precisión visual consecuente) puede inducir la reminiscencia de otras imágenes, todas ligadas a símbolos de muerte, de infierno, de profundidades infraterrenales. De allá la actuación del sujeto, impregnada por el miedo y el distanciamiento que trata de alcanzar frente a ese espacio en particular.

El estudio de los imaginarios urbanos debe, entonces, y en ese contexto, interesarse por las imágenes y la carga imaginaria que le fue impresa por el receptor, lo que implica que es preciso poner al sujeto frente a la imagen, sea por medio de la exposición directa (percibir visualmente un espacio), sea recurriendo a una imagen captada previamente por medios tecnológicos o artísticos (pintura, fotografía, video...). Sin lugar a dudas, la exposición directa del sujeto al espacio le permite una percepción mucho más realista, ya que la dominante ocular no implica que los otros sentidos pierdan fuerza en el proceso integral 
de la percepción. Aun así, en la nueva vivencia de un espacio conocido y percibido, a través del proceso de reminiscencia visual (consultando una fotografía, por ejemplo) es posible reconstruir mejor, aunque no exhaustivamente, las imágenes más complejas que fueron captadas originalmente y transformadas por el imaginario.

Regresando a la observación simmeliana con respecto a la intensidad de la exposición a imágenes en la ciudad, una consecuencia evidente de esa circunstancia se halla en la intensidad extrema con la cual trabaja el imaginario del urbanita. En otros términos, el sujeto en la ciudad está en proceso de vigilia de manera casi permanente, y por ello mismo reconstruye sin cesar sus acervos de imágenes. Así, la imaginación trabaja intensamente en ese andar que va de la percepción original del entorno visual a la construcción de un imaginario por contraste, es decir, un imaginario que se enfrenta a la existencia de imágenes anteriores que tejen, por complementariedad o bien por oposición, el imaginario mismo del espacio de referencia. Es, en este sentido, que se pueden comprender ciertos procesos de doma (o de manejo, configuración...) del espacio que se producen, cuando se frecuenta de manera repetida un cierto espacio. Este tipo de situaciones permiten el acostumbramiento a lugar, aun cuando las imágenes primigenias activaron un imaginario que remite a percepciones cargadas de sentidos negativos, como el miedo, la angustia, etc.

En ello también jugará un papel importante la información transmitida por los medios masivos de comunicación, pero también por la intercomunicación entre personas, considerando que no es exclusivamente información visual. En la actualidad, es cada vez más evidente que todo evento deviene en espectáculo dentro de esta fase del capitalismo, la del espectáculo integrado propuesta por Debord $(1992)^{10}$. En el primer caso -y en esa tónica de la transformación del evento en espectáculo- es frecuente que se tenga información

\footnotetext{
10 Debord se había referido anteriormente a dos formas de espectáculo: el concentrado (fruto del dirigismo tipo fascista) y el difuso. En sus comentarios a la sociedad del espectáculo (1992), admite que en los veinte años entre su primera obra y esta nueva, se ha asistido a la integración entre las dos formas de sociedad del espectáculo.
}

construida previamente sobre un lugar aún no visitado, información que puede ser radicalmente desmentida por la percepción directa no dirigida. Esta forma de concebir la creación de los imaginarios merecería ser aplicada a ciertos segmentos sociales. Un ejemplo, es el caso de los turistas ${ }^{11} \mathrm{o}$, en otro contexto, los migrantes internacionales. En un mundo como el actual, donde la capacidad de acceder a la información sobre los lugares -aun remotos- se ha expandido notoriamente por medio de la Internet y también de otros medios audiovisuales, los turistas suelen viajar con un conocimiento previo, que actúa como nociones predadas y orientadoras de la percepción en consonancia con ciertos imaginarios, definidos externamente a este sujeto. Esta circunstancia se puede confirmar, por ejemplo, al examinar la fuerte y casi necesaria asociación entre la palmera, lo tropical y el sentido de bienestar, como una trama de sentido fuerte en los imaginarios turísticos que se ofrecen al turista.

\section{Los estudios sobre imaginarios urbanos}

No es objeto de este trabajo revisar detalladamente todos los trabajos que se han generado en los últimos años en torno a los imaginarios urbanos. Aunque dicha tarea parece necesaria, exigiría una profunda atención a la forma de concebir los imaginarios en cada caso ya que, como se sostuvo anteriormente, no faltan los trabajos donde la palabra imaginario es la llave mágica de una escritura que versa sobre todo y cualquier cosa.

Quizás una de las diferencias mayores que se pueden detectar en ese universo amplio de los estudios sobre imaginarios urbanos, es la que se puede establecer entre aquellos análisis que remiten a la ciudad vivida y aquellos otros que se centran en las representaciones de la ciudad.

\footnotetext{
$11 \quad$ Para ejemplificar el primer caso, nos referiremos a los estudios realizados por geógrafos alemanes en torno al profesor Erdmann Gormsen; analizaron la percepción del espacio de Acapulco por parte de los turistas alemanes: una gran parte de ellos manifestaron su desagrado por el contraste entre las imágenes publicitarias de ese destino y las imágenes que podían captar durante su estancia del anfiteatro urbano que rodea y domina la franja costera turística a lo largo de la Bahía: dominó la imagen de la pobreza sobre la publicitada calidad turística.
} 
El primer tipo es, sin lugar a dudas, el más frecuente. Son los abordajes que introducen la cuestión de la vida urbana, rescatando un tema que se había obliterado desde décadas atrás, salvo en autores como Pierre Sansot. Este antropólogo francés legó una vasta producción sobre el tema, que solo adquirió sus cartas de nobleza muy tardíamente: hace aproximadamente diez años, cuando su famosa Poétique de la ville fuera publicada en 1984, momento en que el marxismo estructuralista aún hipnotizaba a no pocos investigadores (Sansot, 1984). Habrá que recordar que el tema de la vida cotidiana, ya tratado magistralmente por Henri Lefebvre en varios libros (Lefebvre, 1958, 1961, 1981; Lindón, 2004), había sido relegado de los estudios urbanos o, en el mejor de los casos, transformado en el reflejo de las vicisitudes de la vida degradada ofrecida por el capitalismo, es decir una vida urbana subsumida a la economía y a la dominación política capitalista.

El tema de la vida urbana, como parte de los estudios recientes sobre los imaginarios urbanos, introduce, efectivamente, una dimensión nueva: el interés por esas pequeñas personas (gens de peu) que analizó Sansot en su tiempo, por sus formas particulares de apropiarse del espacio urbano, de organizarlo para garantizar no solo su supervivencia urbana, sino mucho más allá, la vida urbana misma. Temas específicos, como el transporte (Monsiváis, 1995; García Canclini et al., 1996; Narváez, 2000), el uso y la apropiación de las unidades habitacionales, los usos de espacios particulares -semi públicos-, como salones de bailes, discotecas, centros comerciales y otros, han llevado a un mucho mejor conocimiento de las prácticas cotidianas de la población de las ciudades (Kuri y Aguilar, 2006). Sin embargo, si estas prácticas están efectivamente relacionadas con ciertos imaginarios como se desprende de lo que afirmamos anteriormente, pocos son los estudios en los cuales esta reflexión es evidenciada. En otros términos, en el estudio de las prácticas individuales y colectivas en el espacio urbano, como señas y marcas de la vida urbana, estas no siempre están asociadas a los imaginarios que forzosamente las sustentan. Es necesario reconocer, entonces, que se ha producido un gran acervo de análisis culturales sobre la ciudad, cuyo amarre con el estudio de los imaginarios suele ser bastante débil.
No obstante, una relectura, una aproximación de segundo grado de muchos de estos trabajos, permite identificar por lo menos ciertos ejes de sentido como los llama Armando Silva (1992). Estos ejes de sentido remiten, entre otros, a la dificultad de ser modernos, o a la fascinación por la cultura popular como afirmación de una identidad latinoamericana más potencial quizás que real. Todos estos temas han sido abordados por autores como Néstor García Canclini (2004; 1997) o por el mismo Armando Silva (1992), para solo citar los autores más relevantes en estos temas.

A pesar de todo esto, parecería que aún está pendiente la tarea de construir un verdadero amarre entre las prácticas, los ejes de sentido y los imaginarios. Evidentemente, esto no se resuelve por la frecuencia con la cual se emplea la voz imaginario.

Una segunda veta es la de un conjunto de estudios centrados en las representaciones. Este tema se acerca mucho más a lo que podemos considerar como auténticos estudios de los imaginarios: implica entender cómo se forman las representaciones (la ciudad imaginada) de los habitantes de una ciudad. Esta forma de abordaje es la que se introduce en la serie de obras sobre ciudades iberoamericanas, que dirige Armando Silva (por ejemplo Ossa y Richard, 2004; Escoda, 2004 o Silva, 2003). En todos los casos, nos resulta un esfuerzo particularmente útil a partir del momento en que trata de reconstruir la visión de la ciudad que impregna la mente de sus habitantes.

Una de las preguntas más agudas en ese sentido, es la que formula Silva en la introducción a la obra Barcelona imaginada: “AAcaso no son reales nuestras fantasías que soportan los fantasmas?" (Silva en Escoda, 2004: p. 18). En otros términos, asistimos a un interés creciente por entender las representaciones de la ciudad - la ciudad imaginada- que construyen, individual y colectivamente, los ciudadanos de las urbes iberoamericanas. Como también lo afirma Silva y se constituyó un consenso entre los estudiosos del tema, estamos frente a diversas culturas de la ciudad, y no a una sola como los grandes discursos de décadas pasadas quisieron afirmar e imponer como visión de la ciudad (Silva, 1992). Si bien todas las ciudades no 
se construyen solamente sobre la fantasía como Las Vegas o ciertas ciudades turísticas, ciertamente las urbes latinoamericanas merecen ser analizadas a la luz de los fantasmas que sustentan las fantasías de los grupos sociales.

Así, los deseos de modernidad o posmodernidad se entrecruzan y en ocasiones se enfrentan frontalmente con aquellas visiones conservadoras, que también podemos señalar como patrimonialistas, para las cuales la ciudad no debe ser incluida en el movimiento y la aceleración propia de los tiempos actuales. Representaciones conflictuales (Hiernaux, 2006b) que confirman que las diversas culturas de la ciudad no son ni complementarias ni homogéneas, ni forzosamente compatibles.

El tema que introdujimos en los primeros párrafos de este ensayo -la posible desaparición de la ciudad- es otra forma de construcción de las representaciones de la ciudad, y por ende, deriva en imaginarios significativos. Desde las obras fundadoras de Françoise Choay (véase varios textos de la autora, republicados en Choay, 2006), se ha derramado mucha tinta en torno a la desaparición posible de la ciudad, en el sentido tradicional (Hiernaux, 2006c). Esto ha sido magnificado últimamente en el pensamiento de autores como Soja (2001), entre muchos otros, sobre la ciudad americana. En general, esto se constata en los estudios que parten del paradigmático caso de Los Ángeles, la anti-ciudad americana por excelencia, pero también modelo de no pocas experiencias recientes de urbanización tanto en América Latina como en Europa, siempre muy atenta al mantenimiento de la ciudad de tipo mediterráneo (Monclus, 1998) $)^{12}$. Un imaginario significativamente potente

12 Ley y Mills (1993) proponen una crítica particularmente demoledora del trabajo de Soja sobre Los Ángeles, señalando que, en buena medida, esta visión muy negativa de la ciudad proviene de la perspectiva misma del autor, una visión exocéntrica que no forzosamente es la percepción de sus habitantes. Inclusive observan que los autores que siguen esta corriente de análisis de la ciudad posmoderna suelen usar y abusar de una serie de imágenes (imaginery) preestablecidas de control social, muy en la línea de la Escuela de Frankfurt (2002: p. 372). En este sentido, podemos afirmar que Soja ha colaborado en la construcción de un imaginario de Los Ángeles, que ha permeado en los estudios urbanos latinoamericanos gracias a las constantes reediciones de los trabajos claves que ha escrito en esta línea. Pero no por ello, la visión desde la vida en la ciudad, es esa que imagina el autor. atraviesa, así, muchos trabajos contemporáneos: la ciudad tradicional se pierde y con ella el sentido mismo de la urbanidad y la perpetuación del carácter urbanita de la sociedad.

Este potente imaginario no solo deriva en constataciones y discursos sobre el devenir de la ciudad, sino que se pone en operación a través de prácticas urbanas particularmente dinámicas que implican, entre otros aspectos, cuestiones como la recuperación de los centros históricos por aquellos grupos que sienten la necesidad de sostener su carácter urbanita. Así, la gentrificación, generalmente asociada a cambios sociales y a procesos económicos, merece, entonces, también ser vista a la luz del imaginario de la des-ciudad-ización. Evidentemente, este imaginario está construido a partir de imágenes de gran fuerza, como aquellas con las cuales se alimenta nuestra vida cotidiana, en amplias autopistas saturadas, suburbios interminables y una centralidad consumista, que reemplaza a aquella que se construyó progresivamente a partir de diversos procesos históricos y sociales.

Entre la gran cantidad de estudios actuales sobre la ciudad se destaca un segundo grupo de estudios que son aquellos que introducen el tema del miedo, la inseguridad, el encierro y las topofobias como imaginarios dominantes (por ejemplo, Lindón, 2006a). Esta situación no es exclusiva de Iberoamérica: la revuelta de las periferias francesas del otoño 2005, también ha dado lugar a numerosos trabajos en ese sentido (Viala y Villepontoux, 2007). Destaca en todos estos estudios la presencia de un ingrediente que siempre existió en las ciudades pero que se magnifica actualmente e inclusive, se vuelve un argumento político ${ }^{13}$ : el miedo al otro.

El reconocimiento de la presencia del otro que construye su ciudad con representaciones y actúa bajo la fuerza de imaginarios distintos y que a veces llegan a entrar en conflicto con los propios, es fuente de un sentido de inseguridad (aunque sea más una imagen que una realidad en muchos

\footnotetext{
13 Como cuando Nicolas Sarkozy, entonces ministro del interior francés, prometió a vecinos asustados, en el apogeo de los disturbios de 2005, que iba a limpiar la chusma - la racaille- con Karcher (una conocida marca de aspiradoras y equipos de limpieza de gran potencia).
} 
casos). Los investigadores de lo urbano han sido muy sensibles a esas representaciones de la inseguridad, y han dedicado numerosos trabajos sobre el tema (Aguilar, Lindón y Hiernaux, 2006).

Ligada a lo anterior, se encuentra una tercera vertiente o grupo de trabajos relacionados con la forma bajo la cual estos imaginarios se traducen en estrategias concretas, es decir, en acciones sobre lo urbano, para garantizar la protección propia. Este tema es importante en sí porque demuestra la relación entre imágenes, representaciones, imaginarios y acciones, pero además porque permite comprender muchos de los cambios morfológicos de las ciudades actuales, y en este caso, no solo las iberoamericanas (Soja, 2001). Esta perspectiva también ha hecho posible abordar esta problemática a diferentes escalas. Por ejemplo, Alicia Lindón (2006) plantea en este sentido -con relación a un espacio de reducidas dimensiones, o gran escalala reconstrucción de la casa como forma material y como espacio apropiado, en términos de un espacio búnker.

Sin embargo, la vía más relevante, en nuestra opinión, aún no cuenta más que con pocos seguidores, y es la que se plantea la articulación entre los imaginarios y las prácticas ${ }^{14}$. Seguramente, esta vía resultaría fructífera para abordar temas como el de la inseguridad en la ciudad. Pero, aún suelen resultar enfatizadas las estrategias prácticas, y olvidando que su articulación con los imaginarios permitiría comprender de manera más acabada la ciudad actual.

Ciertas líneas del análisis sobre la ciudad que fueron descifradas por el pasado, merecen nuevamente la atención, en el contexto del interés por los imaginarios. Un caso particularmente relevante es el del estudio del discurso de quienes diseñan y aplican las políticas públicas. Aunque no exclusivamente, esto también se puede extender al análisis de los discursos de la sociedad en general con respecto a esas políticas urbanas (Hiernaux y Lindón, 2004). Este discurso refleja imaginarios

\footnotetext{
Es la vía que desarrollamos por ejemplo con relación a los imaginarios sobre el centro histórico de la ciudad de México (Hiernaux 2006b) y que también plantea Lindón (2006) con relación a la casa bunker como consecuencia de la difusión de los imaginarios de miedo.
}

presentes en la sociedad en ese tiempo, y en la sociedad en la cual se desarrolla esa propuesta. Una cuestión crucial, ya añeja en los estudios urbanos, sería establecer qué grupos sociales logran imponer sus representaciones e imaginarios en el discurso de los hombres políticos y cuáles son los mecanismos para imponer estos discursos a nivel de la sociedad en general, así como el esclarecimiento sobre las formas en las que se concretan estos imaginarios en las intervenciones públicas.

En este contexto, operaciones de renovación urbana como pueden ser las de Puerto Madero en Buenos Aires, el Centro Histórico de La Habana o el de la Ciudad de México, parecerían expresar imaginarios que se derivan de ciertas representaciones de lo que es (o debería ser) la ciudad. Sin embargo, se imponen en contextos políticos e históricos particularmente distintos entre sí y en economías y sociedades notablemente diferentes. Ello nos permite preguntarnos: ¿̇erá que existe una cuenca semántica universal -como lo afirma Durand- que en estos casos justifica el discurso de políticos distintos y orienta el curso de la acción pública en operaciones, que si no son semejantes al menos resultan paralelas?

Este trabajo de análisis es todavía una asignatura pendiente, como muchos otros en torno al estudio de los imaginarios urbanos. La fiebre culturalista que encendió en el mundo académico, ha orientado a no pocos investigadores, a acercarse a la vida cotidiana de los habitantes (jel urbanita será ahora un nuevo cobayo que viene a sustituir al proletario?), pero simultáneamente los ha distanciado del análisis de los discursos y de la obra pública o privada. Tal vez sería de mayor potencialidad buscar los puentes entre ambos.

\section{Perspectivas}

No cabe ninguna duda acerca del enriquecimiento que le ha representado actualmente a los estudios urbanos, los aportes de aquellos abordajes que se centran en los imaginarios urbanos. En este camino es necesario destacar, muy particularmente, la brecha trazada por Armando Silva, que ha sido el detonador de no pocas vocaciones en esta vía. También son meritorios los aportes de quienes, como Néstor García Canclini, manejan 
una metarreflexión sobre el tema y alimentan de manera constante y oportuna, la renovación de los estudios urbanos que tanto se hizo esperar.

Sin embargo, la telaraña de los llamados estudios culturales sobre la ciudad no siempre se canaliza hacia un buen entendimiento de los imaginarios ni de la ciudad. Podemos entonces entender esta situación como el resultado de una suerte de fiebre inicial, que conlleva a un florecimiento de trabajos sin que se haya terminado de analizar con detenimiento lo que significa realmente hablar de imaginarios en los estudios urbanos.

En este sentido, una primera perspectiva que nos resulta relevante es la que supone un reforzamiento de las líneas teóricas abiertas por Gilbert Durand (aunque no exclusivamente las de este autor) y que han sido recuperadas con buena fortuna por sociólogos, geógrafos y antropólogos, entre otros. La necesidad de pescar en las aguas turbias de la multidisciplinariedad resulta ineludible. La multirreferencia disciplinaria, aunque a veces puede parecer arriesgada, es la forma más evidente de encontrar su camino en estos temas, actitud que asumen además los autores que citamos a inicios de estas reflexiones finales.

Todo parece indicar que existe aún una gran dificultad en remontar la filiación de las prácticas y las representaciones hacia los imaginarios, y mucho más aún si se pretendiera llegar hasta lo que Durand llamó las estructuras antropológicas del imaginario. Para ello, será pertinente recordar que, si bien las cuencas semánticas parecerían ser universales, cada cultura construye sus imaginarios a partir de sus propias experiencias. La distinción entre lo universal y lo particular puede ser también una línea fructífera de trabajo, especialmente en América Latina.

Por otra parte, cabe subrayar que el sujeto urbano sobre el cual se ha canalizado la investigación actual sobre los imaginarios urbanos son las clases populares, como consecuencia de una larga tradición de trabajo sobre las mismas por parte de la investigación urbana latinoamericana.

Algunas excepciones pueden ser los estudios sobre los nuevos fraccionamientos cerrados (Borsdof,
Hidalgo y Sánchez, 2006; Lacarrieu, 2002; Levi, Méndez y Rodríguez, 2006) o aquellos orientados a ciertas industrias culturales, todos referidos más bien a estratos sociales medios. Aunque hay que observar que suelen eludir las referencias directas a los imaginarios, ya que integran esta dimensión solo de forma colateral o implícita. Sin embargo, parecería que los grupos dominantes tienen un papel decisivo en la construcción de los imaginarios urbanos actuales: por una parte, imprimen su sello sobre la producción de los medios masivos de comunicación que orientan ciertos imaginarios por el bombardeo de imágenes que ofrecen. También son estos actores quienes construyen con frecuencia una relación simbiótica con los grupos políticos en el poder, aun cuando son aparentemente de izquierda como es el caso en la Ciudad de México, teniendo así un papel destacado en la producción del espacio urbano y determinando nuevas pautas de apropiación del mismo. Cabe entonces considerar que serían necesarios estudios realizados de manera profunda sobre los imaginarios urbanos de estos grupos dominantes, así como sus implicaciones en el espacio urbano.

Finalmente, no podemos dejar de subrayar que, aun cuando los imaginarios provengan de imágenes, expresan también la realidad material percibida, aunque reconstruida. La implicación de esto es que la materialidad, lejos de difuminarse haciéndose materia de estudio de abordajes exclusivamente subjetivos, se torna central para el estudio de los imaginarios urbanos. Es quizás hacia antecedentes más lejanos, aunque cada vez intelectualmente más cercanos a nosotros, como Sigfried Kracauer y sobre todo Walter Benjamín, hacia adonde conviene orientar nuestras miradas para una mejor comprehensión de la relación entre la materialidad y la subjetividad, encontrando un sabio equilibrio entre la materialidad y la inmaterialidad, balance frecuentemente olvidado en la producción académica actual sobre los imaginarios urbanos.

Una cita final que retomaremos de Gilbert Durand sobre el carácter innovador de lo simbólico, permite concluir - una vez más- sobre la relevancia del tema de los imaginarios y lo simbólico, desde la perspectiva de generar una nueva pedagogía del conocimiento, particularmente útil para los 
estudios urbanos: "el co-nocimiento ${ }^{15}$ simbólico definido de manera triple como pensamiento por siempre indirecto, como presencia figurada de la trascendencia y como comprensión epifánica, parece estar en las antípodas de la pedagogía del saber tal como se ha ido instituyendo en Occidente desde hace diez siglos" (Durand, 1964: p. 22).

\section{Referencias bibliográficas}

Baudry, P. \& Paquot, T. (Edit.) (2003). L'urbain et ses imaginaires. Pessac: Maison des sciences de l'homme d'Aquitaine.

Berger, P. \& Luckmann, T. (1997). Modernidad, pluralismo y crisis de sentido. La orientación del hombre moderno. Barcelona: Paidós.

Borsdorf, A., Hidalgo, R. \& y Sánchez, R. (2006). Los megadiseños residenciales vallados en las periferias de las metrópolis latinoamericanas y el advenimiento de un nuevo concepto de ciudad. En H. Capel \& R. Hidalgo (Ed.), Construyendo la ciudad del siglo XXI: retos y perspectivas urbanas en España y Chile (pp. 323-336). Santiago: Universidad de Barcelona-Pontificia Universidad Católica de Chile.

Cabrales L. F. (Ed.) (2002). Latinoamérica: paises abiertos, ciudades cerradas. Guadalajara: Universidad de Guadalajara-UNESCO.

Chateau, J. (1976). Las fuentes de lo imaginario. México: Fondo de Cultura Económica.

Choay, F. (2006). Pour une anthropologie de l'espace. París: Seuil.

Debarbieux, B. (2003). Imaginaire géographique. En J. Lévy \& M. Lussault (Dirs.), Dictionnaire de la géographie et de l'espace des sociétés (pp. 489-491). París: Belin.

Debord, G. (1992). Commentaires sur la société du spectacle. París: Gallimard.

Dokik, J., Drieux, P. \& Lefebvre, R. (Edit.) (2003). Symboliques et dynamiques de l'espace. Rouen: Publications de l'Université de Rouen.

\footnotetext{
En francés, Durand escribe co-naissance o sea conocimiento pero también como "hecho de nacer con...". Este nacer con es el resultado de un proceso de conocimiento que se deriva de una situación en la cual al analista está en situación de co-presencia con su objeto, posición metodológica que ha sido ampliamente apoyada y divulgada por ciertas corrientes sociológicas actuales, como la que encabeza Michel Maffesoli, cuando habla de una sociología del acompañamiento (Maffesoli, 1993).
}

Durand, G. (1964). L'imagination symbolique. París: Presses Universitaires de France.

(1992). Les structures anthropologiques de l'imaginaire. París: Dunod.

(1994). L'imaginaire, science et philosophie de l'image. París: Hatier.

Eliade, M. (1985). El mito del eterno retorno. México: Planeta-Agostini.

Escoda, F. (2004). Barcelona Imaginada. Barcelona: Taurus.

Fontaine, P. (2003). Psychopathologie de l'espace vécu: contributions à une analyse phénoménologique des altérations perceptives de l'espace. En D. Jérôme, P. Drieux \& R. Lefebvre (Eds.), Symboliques et dynamiques de l'espace (pp. 125144). Rouen: Publications de l'Université de Rouen.

García Canclini, N. et al (1996). La ciudad de los viajeros (travesías e imaginarios urbanos, 1940-2000). México: Grijalbo-Universidad Autónoma Metropolitana Iztapalapa.

García Canclini, N (1997). Imaginarios urbanos. Buenos Aires: Eudeba.

(Coord.) (1998). Cultura y comunicación en la Ciudad de México. México: Grijalbo-Universidad Autónoma Metropolitana. (2004). Diferentes, desiguales $y$ desconectados, mapas de la interculturalidad. Barcelona: Editorial Gedisa.

Grassi, V. (2005). Introduction à la sociologie de l'imaginaire: une compréhension de la vie quotidienne. Ramonville Saint-Agne: Érès.

Guenancia, P. (2006). La critique cartésienne des critiques de l'imagination. En C. Fleury (Coord.), Imagination, imaginaire, imaginal (pp. 43-76). París: Presses Universitaires de France.

Gregory, D. (1994). Geographical Imaginations. Londres: Blackwell.

Gruzinski, S. (1995). La colonización de lo imaginario. Sociedades indigenas y occidentalización en el México español. Siglos XVI-XVIII. México: Fondo de Cultura Económica.

Gwiazdzinski, L. (2005). La nuit, dernière frontière de la ville. París: Editions de l'Aube.

Hiernaux, D. (2002). Turismo e imaginarios. Cuaderno de Ciencias Sociales, 123, 7-32.

$\left(2006^{a}\right)$. Repensar la ciudad: la dimensión ontológica de lo urbano. Liminar, 4, 2, 7-17. 
(2006b). Los centros históricos: ¿espacios posmodernos? (de choques de imaginarios y otros conflictos). En A. Lindón, $\mathrm{M}$. Á. Aguilar \& D. Hiernaux (Coords.), Lugares e imaginarios en la metrópolis (pp. 27-41). Barcelona-México: Anthropos - Universidad Autónoma Metropolitana Iztapalapa.

(2006c). Imaginar la ciudad: ¿hiperurbanización sin ciudad? Cidades, 3 , 5, 67-80.

Hiernaux, D. \& Lindón, A. (2004). Repensar la periferia: de la voz a las visiones exo y egocéntricas. En A. G. Aguilar (Coord.), Procesos metropolitanos y grandes ciudades. Dinámicas recientes en México y otros países (pp. 413443). México: Instituto de Geografía, PUEC, CRIM-UNAM, CONACYT.

(2007). Imaginarios

urbanos desde América Latina: tradiciones y nuevas perspectivas. En Armando Silva (Edit.), Imaginarios Urbanos en América Latina: Archivos. Barcelona: Fundación Antoni Tapies.

Kerényi, K. (2006). En el laberinto. Madrid: Ediciones Siruela.

Lacarrieu, M. (2002). La comunidad: el mundo imaginado en las urbanizaciones privadas de Buenos Aires. En L. F. Cabrales Barajas (Ed.), Latinoamérica: paises abiertos, ciudades cerradas (pp. 177-216). Guadalajara: Universidad de Guadalajara-UNESCO.

Lefebvre, H. (1981). Critique de la vie quotidienne. París: L'Arche Editeurs.

Legros, P. et al (2006). Sociologie de l'imaginaire. París: Armand Colin.

Lévy, J. (2003). Urbanisation honteuse, urbanisation heureuse. En R. Marcel et al, De la ville et du citadin (pp. 75-91). París: Editions Parenthèse.

Ley, D. \& Mills, C. (2002). Can there be a postmodernism of resistance in the urban landscape? En D. Michael, J. Steven Flusty (Eds), Space of postmodernity (readings in human geography) (pp. 371-377). Oxford: Blackwell.

Lindón, A. (2004). Las huellas de Lefebvre sobre la vida cotidiana. Veredas, Revista del pensamiento sociológico, 8, 39-60.

(2005). Figuras de la territorialidad en la periferia metropolitana: topofilias y topofobias. En R. Reguillo \& M. Godoy Anativia
(Coords.), Ciudades translocales: espacios, flujo, representación. Perspectivas desde las Américas (pp. 145-172). Guadalajara: Social Science Research Council-ITESO.

(2006a). Del suburbio como paraíso a la espacialidad periférica del miedo. En A. Lindón, M. Á. Aguilar \& D. Hiernaux (Coords.), Lugares e imaginarios en las metrópolis (pp. 85-106). Barcelona: Anthropos-UAM. (2006b). La casa búnker y la deconstrucción de la ciudad. Liminar, 4, 2, 18-35.

Lindón, A., Aguilar, M. A. \& Hiernaux, D. (Coord.) (2006). Lugares e imaginarios en la metrópoli. Barcelona-México: Anthropos/Universidad Autónoma Metropolitana Iztapalapa.

López Levi, L., Méndez, E. \& Rodríguez, I. (2006). Fraccionamientos cerrados, mundos imaginarios. En A. Lindón, M. Á. Aguilar \& D. Hiernaux (Coords.), Lugares e imaginarios en las metrópolis (pp. 161-170). Barcelona: Anthropos-UAM-I.

Maffesoli, M. (1993). El conocimiento ordinario. México: FCE.

Margulis, M. (Ed.) (1994). La cultura de la noche. Buenos Aires: Espasa Calpe.

Mejía Madrid, F. (2004). Hombre al agua. México: Planeta-Joaquín Mortiz.

Méndez, E. (2002). Espacios de la simulación. En L. F. Cabrales Barajas (Ed.), Latinoamérica: países abiertos, ciudades cerradas (pp. 65-92). Guadalajara: Universidad de GuadalajaraUNESCO.

Monclus, F. J. (Ed.) (1998). La ciudad dispersa. Suburbanización y nuevas periferias. Barcelona: Centro de cultura contemporánea de Barcelona.

Monsiváis, C. (2006). El centro histórico de la ciudad de México. Madrid: Turner.

(1995). Los rituales del caos. México: Editorial Era.

Narváez, A. B. (2000). Crónicas de los viajeros de la ciudad. Mendoza: Universidad de Mendoza-Universidad Autónoma de Nuevo LeónEditorial IDEARUM.

Ossa, C. \& Richard, N. (2004). Santiago imaginada. Barcelona: Taurus.

Reguillo, R. (2001). Imaginarios locales, miedos globales: construcción social del miedo en 
la ciudad. Estudios, revista de investigaciones literarias y culturales, 17, 47-64.

(2000). La construcción social del miedo: narrativas y prácticas urbanas. En $S$. Rotker (Ed.), Ciudadanías del miedo. Caracas: Nueva Sociedad-The State University of New Jersey.

Reguillo, R. \& Godoy, M. (Coords.) (2005). Ciudades translocales: espacios, flujo, representación. Perspectivas desde las Américas. Guadalajara: Social Science Research Council-ITESO.

Reynoso, C. (2000). Auge y decadencia de los estudios culturales. Buenos Aires: Gedisa.

Sansot, P. (1988). La poétique de la ville. París: Méridiens Klincksiek.

Silva, A. (1986). Las grandes urbes y la vida del espíritu. Ensayos de crítica de la cultura, 198, 247-263.

(1992). Imaginarios urbanos: cultura y comunicación urbana. Bogotá: Tercer Mundo Editores.
(2001). Imaginarios: estética ciudadana. En A. Vergara Figueroa (Coord.), Imaginarios: horizontes plurales (pp. 107-130). México: CONACULTA.

(2003). Bogotá Imaginada. Barcelona: Taurus.

Simmel, G. (1991). Secret et sociétés secrètes. Estrasburgo: Circé.

Soja, E. (2001). Postmetropolis: critical studies of cities and regions. Oxford: Blackwell.

Vergara Figueroa, A. (Coord.) (2001). Imaginarios: horizontes plurales. México: CONACULTA. (2006). Niveles, configuraciones y prácticas del espacio. En P. Ramírez Kuri \& M. A. Aguilar (Coords.), Pensary habitar la ciudad: afectividad, memoria y significado en el espacio urbano contemporáneo. Barcelona: Anthropos-UAM-I.

Viala, L. \& Villepontoux, S. (Dirs.) (2007). Imaginaire, territoires, sociétés: contribution à un déploiement transdisciplinaire de la géographie sociale. Montpellier: Université Paul Valéry. 